\title{
460807 - USE OF TRANSESOPHAGEAL SPECKLE TRACKING ECHOCARDIOGRAPHY TO EVALUATE RIGHT VENTRICULAR LONGITUDINAL STRAIN DURING CARDIAC SURGERY
}

\author{
Matthias Desmet, MD, Richard Bowry, MB BS, Claude Tousignant, MD \\ Anesthesia, St Michael's Hospital, Toronto, ON, Canada
}

Introduction: Right ventricular (RV) dysfunction may be an important predictor of outcome in cardiac surgery. RV assessment is challenging owing to its complex geometry and poor endocardial definition. We assessed the intraoperative feasibility of measuring longitudinal RV strain using speckle tracking.

Methods: After REB approval and informed consent, 23 coronary artery bypass surgery patients were enrolled. Exclusion criteria were: pulmonary hypertension, left ventricular (LV) $\mathrm{EF}<35 \%$, non sinus rhythm and contraindications to TEE. After induction of anesthesia and introduction of a pulmonary artery catheter (PAC), transthoracic (TTE) and TEE were performed. The average of three loops was used for analysis. Studies were stored digitally and analyzed off-line. The RV was divided into 6 segments; 3 septal and 3 lateral. Segments were accepted or rejected for analysis depending on a software determined tracking score. Hemodynamic parameters were collected at time of examination. Pairwise comparisons were accomplished using Anova on Ranks (Dunn's method).

Results: 21 patients were included resulting in a total of 63 assessments per segment. The mean age was $63 \pm 9 y r s$, there were 4 females and 17 males with mean BSA $1.9 \pm 0.2 \mathrm{~m} 2$. Hemodynamic data are presented in table 1 . More segments of the RV could be assessed using TEE than TTE (figure A). A global strain could be determined more frequent using TEE than TTE (73\% vs 38\%). Fewer lateral segments were assessable using TTE. Using TEE, longitudinal strain increased significantly from the base to the apex in the lateral wall (figure B). No difference in strain was observed between the segments of the septum. The mean global strain was $-20.3 \pm 9.7 \%$.

Discussion: Intraoperative speckle tracking for the evaluation of RV strain is feasible. TEE was more reliable than TTE in ventilated patients. Despite this, $27 \%$ of TEE loops could not be used to assess global strain. The segment with the lowest reliability using TEE was the basal lateral wall (76\% of segments assessable). TEE strain patterns of the lateral and septal walls were consistent with previously reported TTE color tissue Doppler-derived strains.

References: 1. Ultrasound in Med.\& Biol 2001; 27: 1087-1097. 2. Echocardiography 2007;24:522-32 3: Cardiovascular Ultrasound 2007;5:7 


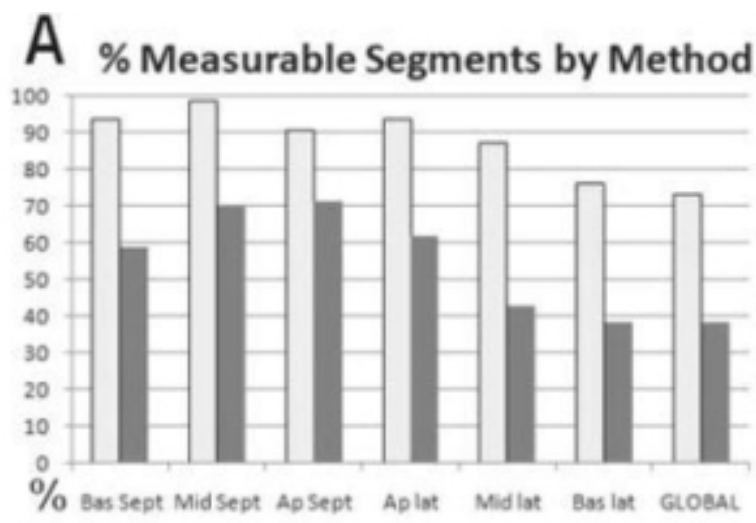

\section{Table 1:}

\begin{tabular}{c|c}
$\mathrm{HR}(\mathrm{bpm})$ & $61 \pm 10$ \\
\hline $\mathrm{MAP}(\mathrm{mmHg})$ & $72 \pm 15$ \\
\hline $\operatorname{MPAP}(\mathrm{mmHg})$ & $20 \pm 6$ \\
$\mathrm{CVP}(\mathrm{mmHg})$ & $13 \pm 3$ \\
$\operatorname{PCWP}(\mathrm{mmHg})$ & $15 \pm 3$ \\
\hline $\mathrm{CI}\left(\mathrm{I} \cdot \mathrm{min}^{-1} \cdot \mathrm{m}^{-2}\right)$ & $2 \pm 0,4$ \\
$\operatorname{LVFAC}(\%)$ & $43 \pm 9(\mathrm{n}=14)$ \\
$\operatorname{LVEF}(\%)$ & $56 \pm 14(\mathrm{n}=10)$ \\
\hline
\end{tabular}

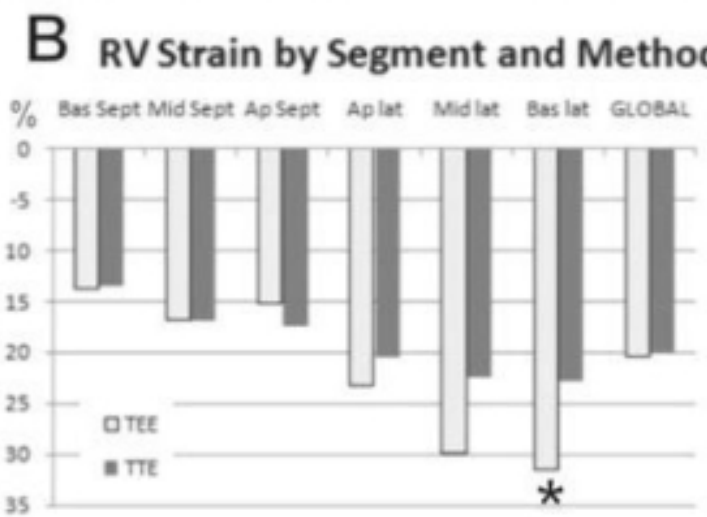

Fig A and B: * Denotes significant difference between basal, mid and apical lateral segments 